\title{
LO MÍTICO Y LITERARIO EN LAS ISLAS DESCRITAS POR EL HISTORIADOR HUMANISTA HOLANDÉS ISACIUS PONTANUS (1571-1636)
}

\author{
Eustaquio Sánchez Salor \\ Catedrático jubilado de la Universidad de Extremadura \\ esanchez@unex.es
}

\section{RESUMEN}

En 1611 Ioannes Isacius Pontanus (1571-1639), historiador humanista holandés, publica una Historia urbis et rerum Amstelodamensium, donde recoge y describe las navegaciones que los holandeses hicieron a finales del siglo XVI camino de las Indias orientales. Se analizan en este trabajo las descripciones de las islas que encuentran los expedicionarios. El trabajo se detiene en la tendencia del humanista que, siguiendo una línea muy antigua en los relatos de viajes, insiste sobre todo en los detalles llamativos, misteriosos, extraños, paradisíacos de las islas. Parece que pretende sobre todo maravillar. Es el misterio que envuelve a las islas, sobre todo si son lejanas y poco conocidas para el público lector.

PALABRAS CLAVE: Ioannes Isacius Pontanus, navegaciones siglo XVI, islas, relatos llamativos.

THE MYTHICAL AND THE LITERARY IN THE ISLANDS DESCRIBED

BY THE DUTCH HUMANIST HISTORIAN ISACIUS PONTANUS (1571-1636)

\section{ABSTRACT}

In 1611 Ioannes Isacius Pontanus (1571-1639), a Dutch humanist historian, published an Historia urbis et rerum Amstelodamensium, in which he describes the sailings that the Dutch made at the end of the $16^{\text {th }}$ century on their way to the East Indies. We analyse in this work the descriptions of the islands found by the expeditionaries. The work focuses on the trend of the humanist who, following a very old line in the storytelling of travelling tales, insists above all on the striking, mysterious, strange and paradisiacal details of the islands. It seems that his aim is to marvel the reader. It is the mystery around the islands, especially if they are distant and unknown to the readers.

KEYWORDs: Ioannes Isacius Pontanus, $16^{\text {th }}$ century sailings, islands, striking tales.

Son muchos los textos que durante los siglos XVI-XVII relatan los viajes marítimos que los europeos hicieron tanto hacia las Indias orientales, como hacia las occidentales en busca de riquezas de diferente tipo. Naturalmente que esos relatos son más frecuentes en los historiadores de Portugal y España que son los protagonistas 
de los primeros viajes hacia los extremos del mar en una y otra dirección. Los humanistas de Portugal se esfuerzan con frecuencia por dejar constancia de las conquistas marítimas de su país, tal como recogen Matos (1984), Costa Ramalho (1998), Sousa Rebelo (1978); a los humanistas españoles les preocupan menos desde el punto de vista historiográfico, los viajes por mar; tenían otras preocupaciones; de todas formas, hubo historiadores y cronistas, si bien no eran estrictamente humanistas; sobre ellos escribe de Vedia (1947).

A finales del siglo XVI protagonizan también viajes de este tipo naciones del norte de Europa. Entre ellas, Holanda. La importancia comercial de estos viajes ha sido ya estudiada; puede verse Gilsanz (2007); pero este trabajo nuestro se va a centrar, no en la vertiante comercial, económica ni marítima, sino en lo literario y fabuloso de las islas descritas por un historiador holandés de la época.

Concretamente, en 1611 Ioannes Isacius Pontanus (1571-1639), historiador humanista holandés publica una Historia urbis et rerum Amstelodamensium ${ }^{1}$, donde recoge y describe las navegaciones que los holandeses hicieron a finales del siglo XVI camino de las Indias orientales. De este humanista holandés tenemos pocos estudios: una edición de sus cartas (Doorninck-Molhuysen, 1909); referencias en monografía sobre la Holanda de la época (Skovgaard-Petersen, 2001); y algunas reseñas en Enciclopedias. De todas formas, ello no es obstáculo para el análisis que vamos a hacer sobre el texto de la Historia urbis et rerum Amstelodamensium.

En 1594 Holanda organizó una expedición para encontrar el paso del noreste hacia las Indias orientales por encima de Siberia. Esta navegación y otra similar en el año siguiente es dirigida por Cornelis Nay; en ella participan también van Linschoten y Barentsz. Durante la travesía se descubrió la isla del oso, la costa occidental de Nueva Zembla. Siguieron después, a finales de siglo, otros viajes hacia las Indias bordeando Africa por el sur.

Lógicamente los holandeses en estas navegaciones descritas por Pontano pasan por numerosas islas, más o menos conocidas. Nos proponemos en este trabajo recoger los rasgos, no estrictamente históricos y técnicos, sino los más cercanos al misterio y a lo extraño que siempre acompañan en las descripciones antiguas de las islas. Las islas siempre se encuentran envueltas en misteriosas apariencias de plantas, animales, individuos e incluso hechos extraños, que unas veces rozan con la fortuna y otras con el infortunio, pero que todos tienen que ver con lo maravilloso y paradisíaco.

\footnotetext{
${ }^{1}$ Utilizamos la edición Rerum et urbis Amstelodamensium Historia in qua Hollandiae primum atque inde Amstelandiae, oppidique natales, exordia, progressus, privilegia, statuta eventaque, mirabilia cum novis urbis incrementis commerciis ac navigationibus longinquis, aliaque ad politiam spectantia, additis suo loco tabulis aeri incisis, ad haec usque tempora, obseruata annorum serie accurate omnia deducuntur. Auctores Ioh. Isacio Pontano, Amstelodami, an. D. 1611. [https://books.google.es/books?id=dYhnAAAA

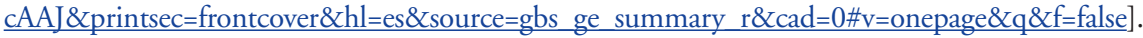


Pero antes de entrar en descripciones paradisíacas, hay que advertir que Pontano, de la misma forma que hacían los humanistas historiadores portugueses y españoles, justifica las navegaciones holandesas. Estas navegaciones están descritas en el libro segundo de la Amstelodamensium Historia, en cuyo capítulo XX comienza el relato de la primera expedición a China por el polo norte (Prima ad Chinam et Molucas boreali via tentata navigatio, p. 128). Pues bien, el humanista holandés comienza la narración de esta primera expedición con estos dos versos de Propercio:

Frangit et attollit vires in milite causa, Quae nisi iusta subest, excutit arma pudor (Prop. 4.6,45-46)

(Es la causa la que rompe o aumenta las fuerzas de un soldado. Si no es una causa justa, la vergüenza rechaza las armas)

Con estos versos justifica las expediciones holandesas: la causa por la que se hacen esas expediciones es una causa justa. Esa justificación se entiende, si tenemos en cuenta que a finales del siglo XVI Holanda está inmersa en una larga guerra con España; a pesar de ello, pretende llegar, como ya han hecho los portugueses, a las Indias orientales, donde contemplaban la posibilidad de encontrar riquezas. Por no pasar zonas controladas por España, intentan una ruta marítima por el Norte de Rusia. Pero al fracasar los intentos llevados a cabo por esa ruta, siguen también el camino del sur, es decir bordeando el Cabo de Buena Esperanza.

Ya hemos dicho que es lógico que en esas navegaciones los holandeses encuentren y pasen por islas. Y el tópico de la isla maravillosa y paradisíaca está presente en el relato de Pontano, como ocurre en todos los relatos de viajes, ya se pase por sitios conocidos, ya por sitios desconocidos o inventados. Dentro de ese tópico vamos a distinguir diferentes ingredientes que consideramos componentes del mismo.

\section{LEJANÍA Y PELIGRO}

La literatura ha cubierto siempre de misterio y peligro a las lejanías. Sobre todo, la literatura de viajes. No falta ese ingrediente en las lejanas islas descritas por Pontano.

Cuando en la Historia de los hechos de Holanda comienza el humanista a hablar de las navegaciones, lo primero que dice es esto:

Ahora, pues, trataré de los peligros nuevos de las expediciones marítimas y de las largas navegaciones nunca antes frecuentadas por los de esta nación ${ }^{2}$.

${ }^{2}$ Nunc ergo nova illa maritimarum expeditionum pericula, navigationesque longinquas indigenis antea nequaquam frequentatas... expediam (fol. 127). 
La novedad de los peligros, la magnitud y lo insólito de los hechos aparecen en estas palabras. Desde un punto de vista programático anuncia ya desde el principio que se va a ocupar de los peligros nuevos; de tierras lejanas antes no visitadas.

En el relato de la tercera expedición al polo norte ocupan lugar importante la lejanía y los peligros por los que pasaron los expedicionarios al tener que pasar el invierno en el polo. Esta tercera navegación al polo norte, Tertia per eundem Septentrionem instituta navigatio eiusque eventus mirabilis (cap. XXII, p. 134) tiene lugar en Mayo de 1596. Al mando de ella estaba Jacob van Heemskerck, siendo su segundo Willen Barentz, acompañados ambos por Jhon Cornelis Ripy.

En esta expedición les sorpendió el invierno en tierras boreales; concretamente en una isla cercana a Nueva Zembla ${ }^{3}$, llamada Auraica; y no pudieron regresar:

Estaba ya acabando el año, ya que era comienzo de Septiembre y el sol se apresuraba a esconderse y ocultarse al otro lado del horizonte de este hemisferio, de manera que no se les iluminaba ninguna esperanza o argumento para salir de allí.

El juego que hace el autor con el doble significado de «iluminar» (de la misma forma que el sol dejaba de alumbrar el lugar, así en la mente de aquellos hombres no alumbraba ninguna esperanza) es un recurso literario para destacar lo peligroso de la situación.

Tuvieron, pues, que pasar el invierno «en una tierra vacía de toda cultura humana, infestada en todo momento de fieros osos, y no tenían ni leños ni troncos ni árboles para construirse en el lugar una choza» ${ }^{5}$. Tuvieron que construir un refugio para el invierno; y el punto de partida para esa construcción es un hallazgo milagroso y extraordinario:

Por una especie de divina providencia sucedió que unos marineros, dando un paseo terrestre de alrededor de una milla en dirección al sur, llegaron a un lugar en el que encontraron un pequeño río de agua dulce y unos leños y árboles enteros que, según parecía, habían sido arrastrados a allí desde el litoral de Tartaria o de otros litorales. Esta tan abundante y tan inesperada abundancia de leños fue suficiente para levantar no sólo un edificio, sino también para hacer un fuego abundante ${ }^{6}$.

${ }^{3}$ Es un archipiélago localizado en el ártico de Rusia, y que consta de dos grandes islas separadas por el estrecho de Mátochkin y una serie de islas menores. Las dos islas principales se llaman isla Séverny e isla Yuzhny.

${ }^{4}$ Erat iam in precipiti anni aestas, utpote Septembris initium totumque se mox abducere atque infra horizontem istius haemispherii occulere sol festinabat, adeo ut inde discedendi nulla affulgeret aut spes aut ratio (p. 135).

${ }^{5}$ in terra ab omni hominum cultu vacua, ursisque saevissimis perpetuo infesta, nec ligna aut tigna arboresve ibi ad casam extruendam uspiam suppeterent (p. 135).

${ }^{6}$ Divina quadam providentia factum ut aliqui ex classiariis terrestri itinere unius fere milliaris, austrum versus, confecto, devenerint in locum ubi et fluviolus dulcis aquae repertus, et ligna et arbores integrae tempestatibus, ut videbatur, e Tartariae aut aliis littoribus eo delatae. Haec lignorum tam larga atque inexpectata copia non aedificio tantum, sed foco etiam extruendo abunde suffecit (p. 135). 
Maravilloso y extraño es encontrar en invierno un arroyo de agua dulce en una isla del polo norte; es de suponer que el autor quiere dejar constancia de que no murieron de sed porque encontraron un arroyo de agua dulce; pero un poco mas adelante dice, como veremos, que una vez construido un refugio, iban al barco que habían dejado en el litoral a buscar todo tipo de sustento; también el agua; de manera que lo más probable es que consiguieran el agua en el barco que habían dejado en el litoral, y que lo del arroyo de agua dulce sea un detalle literario que aumenta el misterio de la isla. Es igualmente maravilloso encontrar unos grandes leños que la corriente marina ha arrastrado desde Rusia a aquella isla. A partir de ese hallazgo, los holandeses construyeron un refugio. Pontano ha presentado la situación como consecuencia de un hallazgo milagroso: encontraron unos leños que habían venido nadando desde el continente, concretamente desde la Tartaria o de otro litoral; eran muchos y muy grandes. Es el gusto por llenar de magia y maravilla lo que sucede en una isla lejana del polo norte en pleno invierno. Pero lo cierto es, como reconoce el propio Pontano a continuación, que construyeron el refugio con materiales procedentes de las naves; nada de hallazgo milagroso:

Las vigas para techar la casa no las podían conseguir salvo en las naves; arrancando, pues, las tablas de los estantes y el tablado inferior de las naves, se llevaban lo que les parecía que podía servirles. Luego, preparando de cualquier manera un pequeño almacén llevan desde las naves comida y lo que les parecía necesario. Y cuando llegó ya el invierno más duro se esconden en este refugio 7 .

Pondera a continuación Pontano las calamidades y peligros que pasaron por el frío, por el hielo, por el hambre, por el humo del fuego que tenían que hacer si no querían morir de frío. Y recuerda el autor las palabras de Virgilio, cuando tras la tempestad descrita en el libro I de la Eneida, dice Forsan et haec olim meminisse iuvabit ("Quizás algún día recordemos esto con agrado») (v. 203); las recuerda, pero las corrige:

Dulce es, dijo aquél, acordarse de las desgracias pasadas. Pero la verdad es, sin embargo, que el ánimo se horroriza al recordar lo que aquellos hombres valientes tuvieron que sufrir en aquel tiempo en un lugar, no sólo vacío de hombres, sino casi condenado por la propia naturaleza ${ }^{8}$.

${ }^{7}$ Asseres ad tegendam domum habere non nisi ex navi poterant: tractis itaque forulis atque inferiori navigii tabulato, quod videbatur in usum suum assumebant. Et mox parata qualiterquecunque aedicula, commeatus e navi et quicquid videretur necessarium exportant; et jam ingruente asperrima hieme, in latibulum istud suum se abdunt (p. 136).

${ }^{8}$ Dulce est, inquit ille, malorum meminisse et tamen meminisse horret animus quaenam interea temporis viri fortissimi pertulerint, loco, ut dixi, non ab hominibus modo vacuo, sed ab ipsa propemodum natura damnato (p. 136). 
Y es que aquellos hombres tuvieron que enfrentrarse constantemente, no solo a la naturaleza, sino a las fieras:

Eran constantes sus enfrentamientos con los osos y los zorros. Frente a los osos sobre todo se vieron obligados a hacer guardias nocturnas, como contra los enemigos. A los zorros acechaban con trampas y cogían no pocos y los comían asados?.

Esos zorros tenían una carne parecida a la de los conejos de Holanda: «recordaban que esos zorros tenían un sabor muy parecido a la carne de nuestros conejos ${ }^{10}$. Sigue describiendo las calamidades sufridas durante aquel invierno por los navegantes holandeses, de manera que el relato de esa expedición se convierte más bien en el relato maravilloso de la superación de una situación extrema por parte de un grupo de hombres en una isla condenada por la naturaleza; así: «Con tempestades muchas veces continuas y que se seguían sin interrupción, en aquel tugurio rodeado y protegido por todas partes por la nieve, apenas podrían aguantar vivos unos cuantos días» ${ }^{11}$. Y además, «alrededor del cuarto día de Noviembre el sol desapareció del todo de su hemisferio, y permaneció invisible y oculto hasta el día veinticuatro de Enero del año siguiente» ${ }^{12}$.

Las calamidades descritas en esta navegación eran tan extraordinarias que el humanista se ve obligado a añadir un capítulo (23 del libro II) para refutar las objeciones de aquellos que dicen que lo narrado es «cosa impensable y totalmente imposible» (rem desperatam et impossibilem omnino), y que consiguientemente «lo más probable es que aquellos hombres no intentaron quizá nunca ni hacer ni acabar lo que se cuenta» (nec factam nec perficiendam fortassis unquam agressos hos homines) (p. 142). Pontano defiende la verosimilitud de las aventuras de esta navegación con un argumento a simili: se podría pensar que también otras navegaciones son imposibles y, sin embargo, sabemos por la historia que ocurrieron; así, la navegación del rey Manuel de Portugal más allá del cabo de Buena Esperanza; la de Vasco de Gama en $1498^{13}$; los exploradores de Alejandro Magno a los que éste ordenó que navegaran desde Etiopía hasta la India; la navegación más allá de dicho cabo que dice Plinio que conocían ya los gaditanos; la que, según el mismo Plinio, llevó a cabo Hannón, rey de Cartago, desde Cádiz hasta Arabia ${ }^{14}$. Y argumenta Pontano: «Si

${ }_{9}$ Perpetuum ipsis praelium cum ursis et vulpibus erat. Adversus praesertim ursos, veluti in hostem, excubias assiduo agere necessum habebant. Vulpibus per decipulas insidiabantur eorumque haud paucos capiebant assatosque edebant (p. 136).

${ }^{10}$ carnem nostratium cuniculorum saporem referre memorabant (ibíd.).

${ }^{11}$ tempestatibus saepenumero continuis ac sine intermissione perdurantibus, in tuguriolo nivibus undique septo munitoque ad dies aliquot tolerare vitam tenebantur (p. 137).

${ }_{12}$ circiter quartum deinde Novembris haemisphaerium ipsorum in totum sol destituit, mansitque ad vigesimam usque quartam Ianuarii sequentis anni invisus atque occultus (ibíd.).

${ }^{13}$ Bajo el reinado de D. Manuel, Bartolome Días descubrió el Cabo de Buena Esperanza en 1488, y Vasco de Gama lo pasó, para llegar a Calcuta, en 1498.

${ }^{14}$ Plinio (N. H. 2. 67) dice que cuando Cartago era una potencia pujante, Hannón bordeó la costa de Gades hasta los confines de Arabia. 
los relatos de los antiguos tuvieron crédito y tuvieron un final feliz, ¿por qué los angustiosos relatos de éstos en su rodeo por el Septentrión no han de merecer ocupar un lugar en la historia como un intento de explorar cuidadosamente el terreno? $\rangle^{15}$. Recoge despues otros testimonios de viajes antiguos a territorio boreal: los Annales francorum danorumque hablaban de que en el año 836 Angarius y Adelbertus, sacerdotes de Cristo, llegaron a Groenlandia; Plinio, citando a Nepote, recuerda que antiguamente se hablaba de un rodeo boreal con ocasión del regalo de unos indios por parte del rey de los suevos a Q. Metelo Céler, procónsul de la Galia, los cuales habrían venido a occidente para hacer comercio a través del océano boreal ${ }^{16}$; citándose a sí mismo, concretamente sus Origines francicae, dice Pontano que se puede pensar que los indios navegaran hasta Germania a través del mar boreal ${ }^{17}$. $\mathrm{Y}$ así sigue con otros testimonios (pp. 143-144).

Es consciente, pues, Pontano de que está contando mirabilia y defiende la credibilidad de las mismas.

\section{LO MARAVILLOSO Y LO EXTRAÑO}

Lo maravilloso y lo extraño está presente en buena parte de las narraciones de navegaciones marítimas lejanas. Hemos visto los enormes y llamativos peligros que pasaron los holandeses cerca de Nueva Zembla en la tercera navegación por el polo. Lo maravilloso y llamativo está presente ya en la primera navegación.

No vamos a entrar en el éxito o fracaso de esta expedición y de las dos siguientes, ya que nuestro objetivo es recoger el tratamiento que un historiador humanista da a las novedades extrañas y desconocidas, sobre todo en el caso de las islas.

En el relato de esta expedición, Pontano da datos técnicos desde el punto de vista náutico y geográfico. Pero se detiene con frecuencia en datos maravillosos y extraños.

Así, el tipo de animales con los que tuvieron que enfrentarse. Cuando los expedicionarios llegan a Nueva Zembla dice el humanista que tuvieron que vérselas, no con piratas ni salteadores, sino "con bestias auténticas. $Y$ es que osos salvajes y verdaderos cerberos infestaban la tierra, el agua, el hielo y casi todo» ${ }^{18}$. La nota clásica

${ }^{15}$ Si haec veterum testimonia apud lusitanos et fidem atque eventum felicem habuerunt, cur non etiam eorundem de circuito Septentrionis suffragia locum aliquem et rem accuratius explorandi conatum mereantur?

${ }^{16}$ En realidad no es citando a Nepote, sino a Pomponio Mela (libro III, cap. 5).

${ }^{17} \mathrm{La}$ verdad es que primera edición que se conoce de los Originum Francicarum libri VI es de Harderwijk, 1616, mientras que la Historia Amstelodamensium es de 1611. Habría que suponer o bien que hay una edición anterior de Originum o bien que en 1611 tenía ya apuntes de lo que después serían los Originum.

${ }^{18}$ ipsis belluis. Nam ursi saevissimi et plane cerberei, cum terram, tum aquam et glaciem omniaque paene infesta habuerunt (p. 129). 
y literaria del humanista aparece en la comparación de estos osos con el can Cerbero, monstruo de tres cabezas que custodiaba el palacio de Plutón en los infiernos. En la isla de Nueva Zembla cazan morsas, cuya descripción por parte de Pontano se centra en lo monstruoso de este animal:

En el litoral también de Nueva Zembla y de las islas de alrededor, donde el polo llega al grado 77, cazaron muchas morsas: es un tipo monstruoso de pez, más grande que nuestros bueyes, anfibio, es decir, que vive tanto en las tierras como en el agua. Tienen la piel semejante a la del perro marino ${ }^{19}$, y la boca a la de una vaca, con la diferencia de que en la del perro marino sobresalen, a ambos lados, dos dientes, de un codo de largo, cuyo precio es semejante al del marfil ${ }^{20}$.

Sigue narrando brevemente esta expedición, deteniéndose en los detalles más llamativos: del mare Tranquillum dice que estaba infestado de ballenas y de otros monstruos marinos (plenum esse balenis aliisque monstris marinis infestum, p. 130); nótese el recurso literario a la paradoja: un mar llamado tranquilo está lleno de animales turbadores. De manera que en el relato de esta primera navegación holandesa por el norte de Rusia Pontano se dedica, sobre todo, a sorpender con la descripción de monstruos marinos.

En el relato de la primera expedición a Oriente por el Sur (Indica Amstelodamensium navigatio prima eiusque historia ordine posita, cap. 24 del libro II) contrasta Pontano la fiereza de los cocodrilos de Java con su condición de alimento exquisito; es un choque desde luego extraño:

Anidan cocodrilos en los ríos de Java, los cuales escondidos en sus oscuridades lanzan
por sorpresa ataques a los navegantes y se los tragan muchas veces enteros. Nos dicen
nuestros compatriotas que estos cocodrillos son cazados vivos por los chinos con gran
habilidad y que después los alimentan y domestican dentro de sus casas en un lugar
seguro; luego, bien alimentados y gordos, son considerados como manjar delicioso ${ }^{21}$.

No se contenta Pontano con decir lo que es normal en el caso de los cocodrilos: que desde sus escondites bajo el agua lanzan sus ataques y engullen enteras a sus víctimas;

${ }^{19} \mathrm{El}$ canis marinus es, de nuevo, un animal monstruoso. Se ha dicho que se trata de la foca monje; o que se trata del lobo de mar; o tiburones. Es, en definitiva, un monstruo marino.

${ }^{20}$ In littore quoque novae Zemblae insularumque circumjacentium, ubi ad gradum 77 polus attollitur, plurimos walros deprehendere: piscis hoc genus est monstrosum, bubus nostratibus maius, amphibion, hoc est, tam in terris quam in aqua vivens. Cutis cani marino, bucca bovinae similis est, nisi quos binos utrimque dentes prominulos habeat, cubiti longitudine, quorum pretium ebori comparatur (p. 129).

${ }^{21}$ Nidulantur et crocodili in Iavae fluminibus, qui in latebris suis insidias navicilis struentes totos saepenumero homines auferunt. Narrant nostrates crocodilos hosce singulari ingenio a chinensibus vivos capi, intraque aedes certo exinde loco pasci ac cicurari; mox probe pastos pinguesque redditos inter eduliorum delicias haberi (p. 180). 
añade el detalle extraño y llamativo de que los chinos cazan, engordan y se comen a los cocodrilos.

En la tercera navegación por el norte nos encontramos con el legendario árbol que no da frutos, sino gansos. Tras pasar la isla que llamaron ursarum insula, siguieron hacia el norte y atracaron en un golfo del norte de Nueva Zembla. Desde allí divisaron, hacia oriente, dos islas; se dirigen a una de ellas y

Vieron que un bando de ánades, que los nuestros llaman rotgansos, estaban incubando. Los animales, asustados por la llegada de los marineros, salieron de pronto volando. De todas formas, se llevaron un ganso y más de sesenta huevos. Hasta ahora se ha creido que estos ánades nacen de los frutos de ciertos árboles en el litoral de las Hébridas de Escocia, ya que el fruto o pomelo de estos árboles, si cae en agua, genera este tipo de ave, pero el que cae en tierra se seca ${ }^{22}$.

En varios bestiarios de la Edad Media aparece dibujado un árbol maravilloso que en lugar de peras o manzanas da gansos. Uno de los padres de la zoología, el suizo Conrad Gessner (1516-1565), pensó que esto era cierto. Observó que en los troncos de los árboles caídos al mar crecían percebes, cuyo parecido con los picos de algunos gansos es evidente. La leyenda les vino bien a ciertos monjes medievales que, dado que los gansos procedían de los árboles, sostenían que podían comerlos en cuaresma.

En este mismo relato de la tercera navegación, Pontano describe, como ya vimos, el invierno que tuvieron que pasar en el polo los expedicionarios al no poder regresar a Amsterdam. En ese invierno pasan peligros y calamidades. Pero también suceden cosas extrañas y maravillosas. Considera Pontano como admirable el hecho de que durante este tiempo que no hubo sol, los osos, como los hombres, no salieran a la intemperie: «es digno de recordar lo que se añade en el Diario del viaje: que los osos desaparecieron junto con el sol. Y es que durante todo el tiempo que no vieron el sol, tampoco vieron osos ${ }^{23}$. También es admirable el hecho de que, en medio de aquel invierno terrible, celebraran alegremente las fiestas de los Reyes Magos:

Tampoco debemos pasar por alto el hecho de que, estando como estaban en las puertas casi del infierno, no por ello dejaron de acordarse de sus diversiones y pudieron recordarlas en su ánimo celebrándolas. En efecto, en el día festivo que muchos

${ }^{22}$ anseres, quos rotgansas nostri vocant, aliquot animadvertere turmatim ovis incumbentes. Sed adventu classiariorum territi subito avolarunt. Vnum nibilominus et ova insuper 60 secum abstulerunt. Hosce anseres creditum hactenus e pomis certarum arborum in littore Haebridum Scotiae pronasci; fructu nimirum sive pomo earum, qua in aqua decidit, avem eiusmodi producente, qua vero in terras exarescente (p. 134).

${ }^{23}$ Memorabile est quod additur in itineris Diario ursos una cum sole continuo se occuluisse. Nam toto eo tempore quo solem non videbant, nec ursos viderunt (ibíd.). 
generalmente dedican a los tres reyes que las Sagradas Escrituras llaman sabios o magos, entre comida y bebida nombraron mediante parodia y mediante sorteo un rey y celebraron también la fiesta del mismo modo que en los demás sitios ${ }^{24}$.

A continuación, describe la fiesta, que consistió sobre todo en un banquete de vino, biscochos y unas tortas hechas de harina, aceite y agua de nieve; $y$, echando a suerte con papeletas, nombraron al condestable rey de Nueva Zembla. Maravillosa y propia de relatos fantasiosos es esta costumbre, repetida desde la antigüedad, de nombrar jefe de un grupo determinado a un personaje que suple al rey o jefe durante uno o más días.

En la narración de la segunda navegación a las Indias orientales por el sur, del año 1598 (Altera Amstelodamensium ad Indos Orientales navigatio eiusque eventos et felix totius classis reditus, p. 192) presenta unos extraños pájaros de la isla Mauricio:

Había también gran cantidad de pájaros, llamados Walgh-vogels ${ }^{25}$ («ave nauseabunda») por los nuestros, porque cuanto a más distancia y más tiempo se metían en el agua, tanto más se ablandaban y se convertían en no aptos para comer, a excepción de sus pechugas que eran de sabor agradable; pero pasaron muy bien sin comer esas aves, ya que estaban en medio de una gran abundancia de gordos loros y de peces $^{26}$.

Este pájaro, tal como recogemos en nota, ha destacado siempre por sus característica extrañas y exóticas en todas las descripciones que han hecho los viajeros sobre él.

${ }^{24}$ Nec omittendum porro homines in Orci propemodum faucibus in hunc modum constitutos hilariorum nibilominus suorum meminisse, et in animum atque usum etiam revocare potuisse. Nam festus ille dies, qui apud plerosque tribus regibus, quos Sacrae Sripturae sapientes tantum seu magos nominant, dicari genialiter solet, regem inter epula et pocula ludicro modo et per sortem creando, illis quoque eundem ad modum festus tunc habitus (ibíd.).

${ }^{25}$ De llamar la atención sobre esta ave se han ocupado a lo largo de la historia viajeros y estudiosos. Parece que fueron los portugueses los primeros que lo vieron en el año 1497 durante la expedición de Vasco de Gama, quien tras doblar el cabo de Buena Esperanza descubrió una isla a la que llamó «Ilha des Cisnes», porque en ella vieron muchos pájaros parecidos a los cisnes con alas como las de los murciélagos. Alrededor de cien años después los holandeses tomaron posesión de esta isla, a la que llamaron Mauricio; ellos describen a ese pájaro tal como recoge este texto. Descripción parecida, con un dibujo del dodo, es la aportada en De Bry's Descriptio Insulae Do Cerne a nobis Mauritius dicte (1601). Clusius publica un nuevo dibujo grotesco de este pájaro en 1605 (cf. Memoir on the Extinct Wingless Ground-Dove, or Dodo, with a Comparison of the Skeletons of Didus Ineptus and D. (Pezophaps) Solitarius. https://repositories.lib.utexas.edu/bitstream/handle/2152/16251/0041appendix dodo.pdf? sequence $=42 \&$ is Allowed $=y$.

${ }^{26}$ Magna quoque volucrum magnitudo erat, quas Walgh-vogels nostri nominabant, quod quo longius diutiusque elixarentur, magis lentescerent et esui ineptiores fierent, praeter pectora, quae saporis jucundioris deprehendebant; sed facile ab esu harum avium abstinuerunt in magna columbarum et praepinguium psittacorum ut et piscium copia (p. 192). 
De la isla Mauricio recuerda Pontano otros animales maravillosos. Habla de tortugas gigantes:

Encontraron tortugas tan grandes, que cuatro hombres podían ser llevados de un sitio a otro montados en una sola de ellas, aunque al paso de ellas; $y$, por último, dentro del caparazón de una sola podían comer cómodamente sentados diez hombres ${ }^{27}$.

El detalle añadido por Pontano, «aunque al paso de ellas», tiene su explicación: ya le debía parecer a él bastante extraño y maravilloso el tamaño de estas tortugas que podían llevar sobre su concha hasta cuatro hombres, que se ve obligado a añadir que lo podían hacer sí, pero a su paso: ¡sólo faltaba que, además de llevar a cuatro hombres, lo hicieran a velocidad humana! Hay que recordar además aquí que existía una leyenda medieval en la que se hablaba de una enorme ballena sobre la que se asentaron unos frailes dirigidos por San Brandán. La leyenda es recogida en la Navigatio Sancti Brandani, compuesta entre los siglos X-XI, cuyo relato remonta al siglo VI; el monje irlandés Brandán, acompañado de otros catorce monjes, trata de encontrar el Paraíso y para ello navega por el océano Atlántico. En un momento ven una isla que a veces aparece sobre las aguas y otras desaparece. Cuando la encuentran celebran en ella la Pascua. Luego se dan cuenta de que es un enorme pez, sobre cuyo lomo han podido celebrar. En el caso de los holandeses del relato de Pontano se trata de enormes tortugas. No deja de ser un hecho maravilloso.

En el relato de esta misma expedición dice Pontano que, tras pasar el cabo de Buena Esperanza, un grupo de holandeses llegó a la isla de Santa María, que ya habían visitado en la anterior navegación. Otro grupo llegó a la isla Mauricio; Pontano, tras ofrecer datos técnicos sobre esta isla, añade las cualidades extraordinarias de algunos de sus árboles:

a una isla desconocida -algunas la llaman isla do Cerne-, a la que, para que fuera más conocida, pusieron el nombre de Mauricio. El acceso a esta isla tiene un puerto cómodo y una parada muy segura, a la que llamaron Varvico, a partir del nombre del vicealmirante. La isla está situada a alrededor de veinte grados más acá del equinoccio, frente a Madagascar por el sur. En extensión es casi igual que Holanda. A los que llegan a ella por mar les da la impresión de que toda ella es montañosa; sin embargo, tiene dentro muchas llanuras. Abunda en árboles de gran envergadura, cuya madera casi supera en negrura a la pez, y en dureza y pulimento al marfil. Hay también allí árboles o ébanos, del mismo tipo, con la madera roja, otros de color amarillo semejante a la cera... ${ }^{28}$.

${ }^{27}$ Testudines tantae magnitudinis repertae sunt, ut viri quatuor in una conistentes ad gressum eius de loco in locum promoverentur; et denique intra unius testam homines decem considentes commode epularentur... (p. 192).

${ }_{28}^{28}$ ad ignotam insulam-Do Cerne nonnulli vocant-, quam, ut notiorem facerent, Mauricii ei nomen indiderunt. Ad hanc insulam portus est commodus et statio satis tuta, quam Varvicum de nomine Vicealmiralii appellarunt. Insula ad gradus circiter viginti citra aequinoctialem sita est, Madagascari versus Austrum 
Recoge aquí lo sorprendente, lo maravilloso y que llama la atención: la dureza y el color raro de la madera de los árboles.

Entre las incursiones que hacen por los alrededores de las islas durante la segunda navegación por el sur a las Indias orientales se encuentran con una que produce miedo incluso entre los indígenas, ya que piensan que está habitada por demonios malvados:

A través de numerosos vados poco profundos y rocas llegaron a la vista de una isla desierta: la llaman Poelsetton y la tienen mucho miedo, porque piensan que en ella viven demonios malvados. Si por casualidad alguna tempestad los lleva hasta ella, se echan sobre las velas y remos para salir huyendo de allí. En una ocasión en que navegaban pasando de largo cerca de ella, un indio, al que habían cogido algo así como timonel y piloto para salvar los vados y rocas, les produjo risa y gracia. Éste, de pie en la proa y llevando en la mano un harpón o, como se llama vulgarmente, un haeckón, se ayudaba del mismo, para, con gran fuerza, cambiar el rumbo alejando a la isla de él y de las naves. Herido, colocó el harpón de forma que su parte delantera sobresaliera fuera de la nave, y no permitió que fuera quitado de allí, hasta que perdieron de vista la tierra de aquella isla. Cuando estaba ya en Malaca, andaba por las calles hinchado de orgullo y con una música con la que se afanaba o bien en aplacar a los demonios o bien en coger ánimo para sí mismo ${ }^{29}$.

Una isla fantástica en la que viven los demonios y de la que huyen a todo remo y a toda vela. El episodio del indio que habían cogido como timonel es tan fantástico como el miedo a la isla: cual un demonio, aquel indio utilizaba el arpón para alejarse de la isla y luego, cuando ya estaba en Malaca, para aplacar a los demonios. Recordemos que el arpón de tres puntas es el arma con la que el demonio es representado frecuentemente.

Lo sorprendente y lo maravilloso ha sido siempre patrimonio de géneros literarios propios del barroco, entre los que destacan los relatos de viajes; sobre todo

objecta; magnitudine Hollandiae pene aequalis. Adnavigantibus foris tota in montes consurgere videtur, multas tamen intus planities habet. Arboribus mirae proceritatis abundat, quarum lignum picem nigredine, duritia et laevitate politum ebur paene vincit. Sunt et arbores ibi sive ebeni eiusdem generis ligno rubente, aliae instar cerae coloris lutei... (p. 192).

${ }^{29}$ per multa brevia et syrtes in conspectum insulae cuiusdam desertae perveniunt; inde Poelsetton appellant eamque vehementer reformidant, utpote quam esse cacodaemonm domicilium existimant. Si qua forte tempestate in eam deferantur, velis remisque in fugam incumbunt. Hanc ergo dum praeternavigant, risui et voluptati nostris fuit Indus homo, quem ad vada et syrtes istius tractus praecavendas quasi navarchum et pilotam sibi adsciverant; is enim in prora consistens et harpagonem sive, ut vulgo appellant, haeckonem manu tenens, magno veluti nisu insulam a se et navibus avertendo cursum adiuvabat. Fessus harpagonem ita ponit ut anterior eius pars foras promineret, nec auferri eum prius inde sinebat quam e conspectu invisae telluris esset perventum. Malacia cum esset, per foros fistulabundus cursitabat. Et ea quasi musica vel daemones placare, vel animum sibi ipsi addere studio habens (p. 197). 
de viajes marítimos. Es el caso del relato de Pontano, el cual, si bien tiene una parte de relato geográfico y justificativo de expediciones marítimas, también tiene otra dedicada a lo fantástico y llamativo, que es en lo que nos estamos deteniendo.

\section{PRODUCTOS CON CUALIDADES EXTRAORDINARIAS}

En las descripciones de las islas los holandeses insisten también en los alimentos abundantes y salutíferos que encuentran en ellas. Pontano recoge detalles al respecto como un elemento más de la vertiente fantástica y literaria del relato.

Es bien sabido que las expediciones marítimas de los europeos durante los siglos XV, XVI y XVII tienen como finalidad fundamental la comercial. Pero los historiadores, y en concreto Pontano, recogen referencias a productos comerciales que destacan por alguna característica exótica e incluso maravillosa, además de su valor comercial. De la primera navegación hacia las Indias a través del camino del sur, es decir, bordeando África, de la que ya hemos dicho que comienza en 1595, dice Pontano que la armada preparada para ella «fue organizada también para traer todo tipo de mercancías, que se sabía que podían sacar de las Indias» ${ }^{30}$. Dice «también», porque antes ha dicho que el objetivo era náutico y bélico. Pero, además, de las mercancías recuerda con frecuencia que algunas de ellas tienen alguna caractarísica llamativa.

De la morsa que los holandeses encuentran en la isla de Nueva Zembla destaca Pontano que tiene dos colmillos cuyo valor es semejante al del marfil. Y en esa misma misma isla, además de en la isla Ordinum, buscan piedras que se parecen por su brillo a los diamantes: «algunos de ellos, alejándose mucho de los demás, buscan, no sólo aquí, sino también en la isla Ordinum, piedras que se parecían por su brillo a los diamantes» ${ }^{31}$.

En el viaje de vuelta de la tercera navegación al polo norte, en el verano de 1597, contactan con rusos en el sinus sancti Laurentii (golfo de San Lorenzo); tras pasar unos días, los rusos se marchan a su tierra y los holandeses siguen su camino. En el invierno anterior, que, como ya vimos, habían tenido que pasar necesariamente en el polo norte, sufrieron muchas calamidades y estuvieron cerca de la muerte. Pero en la vuelta llegan a una isla cercana al citado golfo de San Lorenzo, duabus crucibus insignitam; desembarcan en ella y

Inopinadamente y para enorme beneficio suyo encontraron la hierba de la coclearia y la comieron entera, como nace y sin condimento, para curarse. Es una hierba seca

${ }^{30}$ ita instructa fuit, ut mercium simul, quas expeti ab Indis constaret, omne genus veheret (p. 145).

${ }^{31}$ unus alterve a caeteris longius aberrans lapillos quaeritat, qui non ibi modo, sed in insula quoque Ordinum reperiebantur, fulgore adamantes referentes (p. 133). 
y cálida ${ }^{32}$, como el berro, y se utiliza especialmente para el escorbuto ${ }^{33}$. Se llama coclearia porque tiene unas hojas cóncavas con la forma no muy profunda de una cuchara $^{34}$.

Es cierto que la coclearia es una planta medicinal, que se encuentra en Europa desde el ártico hasta las montañas del sur, y que había sido utilizada desde la antigüedad como remedio contra el escorbuto. Pero Pontano nos presenta su hallazgo como algo inopinado y como venido del cielo; añade que la comieron sin elaborar, como la da la naturaleza. Son rasgos propios de un paraíso: lo inesperado del hallazgo y su consumición sin cocinar.

En el cap. 24 del libro II, titulado Indica Amstelodamensium navigatio prima eiusque historia ordine posita (p. 144), describe la isla de Madagascar. Esta expedición tuvo lugar en 1595 bajo la dirección de Cornelius Houtmannus. Cuando describe la isla de Madagascar (p. 148), hace un recorrido por todos los beneficiosos productos y animales que hay en ella. Comienza hablando de la fertilidad de la isla gracias a las fuentes que manan en su territorio (Ipsa regio singulari fertilitate praedita. Fontes habet quamplurimos, et aquas dulces atque perennes); tiene densas selvas y bosques (Est praeterea densis sylvis nemoribusque culta); es muy abundante en pesca, caza y aves (Abundat multum piscatu, venatu et aucupio); esta tierra derrama por todas partes diversos tipos de frutales, que producen casi sin cultivo, como el Paraíso (variasque fruges, modica cultura adhibita, profundit); tiene diversidad de raíces, que utilizan como pan (radices multiplices habet, quibus homines vice panis utuntur); está vestida de naranjas, manzanas y otros árboles que exhalan admirables olores (Citreis quoque malis et aliis arboribus odore miro fragrantibus vestita est); hay innumerabes cañas, de las que el azúcar mana por sí misma o es sacada con técnicas (Arundines innumerabiles, e quibus saccharum vel natura instillatur vel artificio exprimitur, in ea late proveniunt); el jengibre nace por todos sitios, del cual se alimentan cuando está verde (Zingiber passim effunditur, quo quidem viridi vescuntur): se cree que tiene también metal de plata (Habere quoque argenti metalla putatur...).

Es una descripción que bien podría servir para cualquier vergel o paraíso de la edad de oro.

${ }^{32}$ Estos adjetivos hay que entenderlos en términos galénicos. Lo seco y lo húmedo, lo frío y lo cálido son las cualidades que se encuentran en los cuerpos y en función del predominio de una $\mathrm{u}$ otra son las propiedades de ellos. escorbuto.

${ }^{33}$ Su alto contenido en vitamina $\mathrm{C}$ la ha convertido en un remedio muy común para el

34 inopinato et magno suo bono cochleariae herbam repererunt eamque totam prout nascitur ac sine condimento valetudinis causa comederunt. Est enim haec herba sicca et calida, uti et Nasturtium estque peculiaris eius in Scorbuto usus. Cochlearia dicitur quod instar cochlearis non admodum profundi concava habeat folia (p. 140). 
Algo parecido ocurre cuando en la primera expedición a Oriente por el camino del sur, describe la isla de Santa Helena (p. 191). Después de que los holandeses habían sido tratados con fidelidad y confianza en Bali y despedidos con amabilidad, el 3 de Marzo de 1595 se echaron a la mar y navegaron ininterrumpidamente hasta el 25 de Mayo en medio de grandes peligros y dificultades (non sine maximis periculis et difficultatibus continenter navigarunt). Esperaban, sin embargo, encontrar alivio tras esos peligros en la isla de Santa Helena, en la que habían decidido hacer escala. Y a partir de ahora viene una descripción de la isla como un auténtico paraíso y vergel:

Es, en efecto, como si esta isla hubiera sido puesta por la divina providencia en medio del ancho océano para solaz de los navegantes: es abundante en fuentes, en cabras y otros tipos de animales, y en frutos de la tierra. No tiene habitantes, porque el rey de España lo ha prohibido mediante edicto, para que nadie fije en ella un asentamiento estable. Sin embargo, los portugueses suelen dejar en ella a los enfermos a su paso hacia la India; y cuando vuelven después, los encuentran restablecidos en su salud y se los llevan. Tiene un puerto, o mejor una estancia muy cómoda, no lejos del cual hay un pequeño templo sagrado con algunos porches para uso de los enfermos. Está toda ella llena de altos montes, en los cuales andan innumerables rebaños de cabras salvajes. Los valles revientan de arroyos y fuentes muy amenos; y están sembrados de frutales de todo tipo, ya nativos, ya traídos de fuera. El aire es salubérrimo; la pesca, tan abundante, que ella sola puede alimentar a una gran multitud de gentes; y lo que es más importante, la provisión de agua está tan al alcance de todos que no puede ser más cómoda ${ }^{35}$.

De manera que a la vista de tal paraíso los holandeses se dirigen hacia él con la esperanza de encontrar remedio para los problemas que tenían (Huc igitur cursum dirigunt, difficultatibus, quibus premebantur, remedia quaerentes).

Similares características paradisiacas son las descritas para la isla de San Mauricio en la descripción que se hace de ella en la segunda expedición a las Indias orientales del año 1598 (p. 192). De ella dice Pontano: «clima saludable, y de un suelo fértil y regado por límpidas aguas ${ }^{36}$. No tiene nada de extraño que los holandeses, al pasar por esta isla tan paradisiaca, quisieran dejar constancia de su paso por ella

${ }^{35}$ Est enim insula haec vastissimo illi mari veluti divino consilio ad navigantium usum iniecta, fontibus, capris aliisque animantium generibus ac terrae fructibus abundans. Incolas nullos habet quod regis Hispaniarum edicto prohibitum sit, ne quis in ea stabilem sedem sibi figat. Solent tamen lusitani ad indias commeantes, aegros hic exponere; quos postea redeuntes pristinae sanitati restitutos inveniunt secumque avehunt. Portum, sive stationem potius, commodissimum habet, a quo non procul sacellum et pergulae quaedam in usum aegrotantium. Tota referta est altissimis montibus, in quibus innumeri caprarum silvestrium greges errant. Valles rivis et fontibus amaenissimis scatent, omnis generis, cum nativis, tum aliunde importatis consitae. Aer saluberrimus est; piscatio adeo copiosa, ut vel sola maximam hominum multitudinem alere possit. Tum, quod caput est, aquatio it commoda, ut commodior optari vix queat (p. 151).

${ }^{36}$ Tota deserta est hominumque et quadrupedum quoque vestigiis vacua, salubri interim caelo et solo fertili, et aquis denique limpidissimis irrigus (p. 192). 
y de su condición de calvinistas. En efecto, sigue diciendo Pontano que recogidas sus fuerzas y con varias naves que habían construido de nuevo o que habían reparado, clavaron una tabla de madera en un árbol, con una inscripción que, en holandés y zelándico, y con las insignias holandesas decía: «Cristianos reformados»" Se conocía como cristianos reformados a los calvinistas holandeses. Con ello querían sin duda dejar constancia no sólo de su paso por aquella isla extraordinaria, sino también de su condición de protestantes frente al rey católico de España que se consideraba dueño de aquella isla.

En la primera navegación a Oriente por el sur, el trece de Enero de 1595, cuando el sol estaba en lo más alto y, por ello, las enfermedades y, sobre todo el escorbuto, se agravaban, decidieron communi suffragio dirigirse hacia Java, y llegaron en primer lugar a la isla de Santa María, pequeña isla al este de Madagascar; y fue gracias a los alimentos y frutos que allí les dieron como lograron sofocar el hambre, pero también curar las enfermedades:

Nada más entrar en el puerto se presentó un habitante de la isla trayendo arroz, azúcar, naranjas, gallinas y otras cosas. Dado que tenían mucha necesidad de estas cosas no sólo como comida, sino también como medicina para recuperar a los enfermos, permanecieron en el puerto aislados durante unos días para alimentarse con las naranjas y los frutos que acabo de citar y con otras cosas ${ }^{38}$.

Desde esta isla de Santa María, vuelven a Madagascar, lo cual es ocasión para describir nuevas cosas de esta isla. Entre otras, alimentos y frutas que remedian el hambre y curan el escorbuto: inter caetera cadi aliquot orizae in singulas naves continuo delati, praeter gallinas, saccharum, citria mala aliaque saluberrimorum fructuum poma, quibus classiariorum scorbutus penitus evanuit (p. 150).

Más adelante, hablando de los frutos de la banana recuerda que algunos los llaman higos del Paraíso (vocantur ab aliquibus fici poma Paradisi); y que los llaman así tanto por la suavidad de su olor y sabor, como por la mucha gracia de su color (tum propter odoris saporisque suavitatem, tum propter summam coloris amabilitatem). Hablar de la suavidad del olor y del sabor y de la gracia del color es un recurso literario para sorprender al lector; con ello, el lector no sabe cuál es concretamente el olor, ni el sabor, ni el color de la banana, pero estéticamente le sirve para comprender que debe ser algo maravilloso. De todas formas, a continuación Pontano baja

${ }^{37}$ Mox recollectis viribus et scapha una aut altera de novo exstructa aut reparata, tabulam ligneam arbori cuidam affigunt, adiectis hollandico, zelandico et Amstelodamensium insignibus cum huiusmodi inscriptione, CHRISTIANOS REFORMADOS (p. 192).

${ }^{38}$ Portum ingressis confestim adfuit insulanus oryzam, saccharum, mala citrica et gallinas aliaque apportans. Quibus rebus cum non ad victum tantum, sed etiam ad aegros reficiendos magnopere indigerent, aliquot ibi dies extracti pomis et fructibus modo dictis aliisque rebus coemendis (p. 150). 
del terreno de lo literario y epatante al terreno de la realidad y añade que el sabor es agridulce, el olor semejante al de las rosas, y el color es verde brillante (Sapor enim ex dulci acescit modice, odor rosarum nostratium est; color vero ex viridi iucunde flavescens) (pp. 151-152).

Durante la segunda expedición a las Indias orientales por el sur, Altera Amstelodamensium ad Indos Orientales navigatio eiusque eventos et felix totius classis reditus, cap. XXV, p. 192), que tuvo lugar en 1598, llegan a la isla de Banta (p. 193) y el primer hecho extraordinario que sucede es que los lugareños, en lugar de expulsarlos como habían expulsado a los portugueses cuando advertieron y se dieron cuenta de los engaños de estos, a ellos, los holandeses, los reciben bien: con gran humanidad y con regalos. En efecto todos los días llevaban a sus barcos gallinas, huevos, cocos, bananas, tortas de arroz y vino chino que conseguían a precio tan bajo que con una cuchara de estaño podían fácilmente conseguir alimento para una semana ${ }^{39}$. Este detalle no sólo sirve para comparar objetivamente la acogida que tenían los portugueses en las islas orientales con la que tienen los holandeses, sino también para destacar lo exótico de algunas mercancías.

En esta misma expedición arriban, entre otras, a Amboyna (p. 196), cercana a las Molucas y distante de Banda alrededor de veinte millas hacia el noroeste. Es una isla abundante en carofila, cítricos, hierbas medicinales, cañas de azúcar, y otros aromas de este tipo, cuyo precio es tan bajo que... ${ }^{40}$.

Cerca de Banda, hay una isla que produce más aromas que alimentos, lo cual no deja de ser una característica afortunada de la misma. En efecto, dos naves holandesas, al no poder cargar del todo sus barcos en la isla Ambyona, se dirigen a una de las Molucas, Ternata:

Esta isla, más feraz en aromas que en frutos, dista de Banda dieciocho millas. En efecto, de aquello que sirve para alimento, hay muy poco; si prescindimos de unas pocas cabras y gallinas, no tiene ningún otro tipo de animal; no produce arroz ni ningún otro producto. Sin embargo, sí tiene pan, que hace a partir de un leño de la siguiente manera: hay allí un tipo de árbol de madera blanda casi reducible a polvo; cortándola en palos delgados los ponen a secar; golpean con un mazo los trozos,

${ }^{39}$ et bantenses quidem, qui tunc, ut supra meminimus, lusitanos, deprehensis atque intellectis eorum fraudibus, territorio eiecerent, summam in nostros humanitatem ac beneficentiam demonstrabant, Quotidie enim gallinas, ova, cocos, bananas, placentas ex oryza confectas, vinumque chinense ad naves deportabant, tanta pretii vilitate, ut cochleari stanneo victum hebdomadalem facile quis sibi parare posset.

${ }^{40}$ quae Moluccis finitima est, Banda circiter milliaria viginti quatuor, occidentem borealem versus, distans... Ferax est carophyllorum, malorum citriorum, medicorum, cannarum sacchari, aliorumque id genus aromatum, quorum tanta est vilitas. 
los cuales reduciéndose a polvo proporcionan una harina. Con ella amasan un pan blanco, de la magnitud de una mano, de forma cuadrada; supone el principal intercambio de mercancía entre los insulares. La isla es abundante en grana, en flores de banana, en manzanas, pero sobre todo en cariofila ${ }^{41}$.

Es sorprendente lo del pan hecho con harina generada a partir de la madera de un árbol; pero más sorprendente es que ese pan sea el principal producto comestible y comercial entre los habitantes de la isla. Tiene, sin embargo, aromas y plantas medicinales que la convierten en un afortunado lugar para los holandeses.

En la descripción de la isla de Ceilán, que se encuentra en el relato de la segunda navegación a las Indias por el sur, destacan los productos exóticos generadores de felicidad y delicia; el propio Pontano, al hablar de los nombres de la isla, dice que uno de ellos significa «tierra de delicias»: «Unos llaman Ceilán a esa isla, otros Zeilon, otros Tenarisi, es decir, tierra de delicias...». Comienza con una característica propia de islas afortunadas, en las que nacen las hierba y plantas de forma espontánea, sin cultivo: «es muy fértil, y no solo abundante en frutos, sino también extraordinariamente dotada de hierbas y plantas que huelen con un olor mirífico; esas hierbas y plantas nacen sin ningún tipo de cultivo»; lo del olor mirífico y lo de la espontaneidad del nacimiento de estas plantas es un rasgo propio de un paraíso. Sigue aludiendo a la especie más característica y abundante de Ceilán: «desparrama además por todos sitios gran abundancia de cinamomo (canela)». Luego a las piedras preciosas y a las gemas: «se sacan también de las vetas de rocas enormes muchas y muy variadas piedras preciosas; se encuentran también, en las ostras sacadas del fondo del mar, gemas en increíble multitud y de singular color y brillantez». Y, por último, la abundancia de elefantes: «además de todo eso, en ella se alimenta un gran número de elefantes» ${ }^{42}$.

${ }^{41}$ abest haec insula a Banda duodeviginti miliaribus, aromatum quam frugum feracior. Earum enim rerum, quae ad alimoniam pertinent, exiguus ibi est proventus; praeter paucas capras et gallinas nulla habet pecora; nec oryzam fert aut aliud frumentum. Panem tamen habet quem e ligno conficiunt hunc in modum: est ibi arboris genus, ligno molli et paene friabili. Succisam in festucas secant. Segmenta malleo tundunt, quae soluta farinam praebent. Ex ea panem candidum pinsunt, palmae magnitudine, forma quadrata: praecipuum insulanorum inter se mercimonium. Cocis abundat, bonanae floribus, malis, sed in primis caryophylis (p. 198).

${ }^{42}$ Appellatur autem ab aliis haec insula Ceilan, ab aliis Zeylon, ab aliis Tenarisim, id est, delitiarum terra... esse autem fertilem admodum, neque solum variis frugibus abundantem, verum et herbis et plantis odore mirifico redolentibus egregie vestitam; quae quidem sine ulla cultura proveniant; magnam praeterea cunnamoni vim passim fundere, et multos praeterea pretiosissimos lapides atque multiplices e saxorum ingentium venis erui; et gemmas etiam incredibili multitudine et singulari colore atque fulgore, extractis ostreis e fundo maris reperiri; ad haec miram elephanorum copiam nutriri (p. 208). 


\section{ENFRENTAMIENTOS CON MONSTRUOS MARINOS}

La descripción de los enfrentamientos y luchas con los monstruos marinos de las islas y del mar es un ingrediente más del carácter fantasioso y maravilloso que rodea a todo el relato; y sobre todo es una muestra de elaboración literaria de una descriptio con todos los ingredientes retóricos y literarios de la descriptio.

En el relato de la primera navegación, en la que los protagonistas son, como dijimos, los monstruos marinos, encontramos ya el episodio de un oso que ataca a una nave:

Uno de los osos, que como todos los demás de esta zona reflejaba con su color la propia nieve, es atravesado por una bola de bombarda cuando, tras saltar del hielo sobre la barca, perseguía a los marineros nadando. Y cuando advirtieron que se lanzaba con gran fuerza sobre la nave, le arrojan un lazo al cuello, esperando llevarlo vivo a Amsterdam; pero al final se tuvieron que conformar con la piel y con los restos, como queda claro de lo que pasó a continuación. En efecto, el oso, arrastrado con el lazo al cuello y siguiendo lentamente a la barca, en cuanto vio la ocasión, saltó sobre la popa de la barca con la parte anterior de su enorme mole, de manera que los marineros, inmeditamente aterrorizados y asustados y refugiados en la proa, habrían acabado en aquel momento, si no hubiera sido porque el lazo al que estaba atado enredándose inopinadamente en la parte inferior del mango del timón frenó su impetuoso primer asalto; inmediatamente, en efecto, un marinero, animado a raíz de eso, atravesó al oso con una lanza, cuando estaba todavía tumbado en la barca ${ }^{43}$.

Es una descripción en la que el autor se deleita en la intriga y la sorpresa: el oso es herido, pero continúa persiguiendo a nado a los marineros; animal herido persiguiendo al que le ha herido es un ingrediente propio de relato de intriga y angustia. Intriga y angustia que llega a un grado mayor cuando el oso salta por sorpresa sobre la nave. $\mathrm{Y}$ al final todo se resuelve con un golpe de suerte sorprendente que no tiene nada que ver con la maña o la fuerza de los marineros: el oso se enreda casualmente en una soga y queda inmovilizado.

En la segunda navegación, Altera per Boream circuitus investigandi periclitatio (cap. XXI, p. 130) destaca el ataque de un oso a los expedicionarios. Según Pontano,

${ }^{43}$ Quorum unus, colore nivem suam, ut et reliqui eo tractu referens, dum e glacie prorepens cymbam quam inscenderat navales natando insectatur, sphaerula bombardica transfixus est. Et nihilominus ad cymbam magno impetu cum ferri animadverterent, tandem etiam laqueum collo iniiciunt, sperantes se vivum Amstelodamum deportaturos, sed corio et exxuviis postmodum contentos fuisse hinc liquet; nam ursus laqueo eum in modum innexus cymbamque lente consequens, capta occasione, anteriori corporis mole in cymbae puppim prorupit, ita ut territis subitoque consternatis classiariis, et ad proram confugientibus, actum de singulis fuisset, nisi laqueus, quo vinctus tenebatur, inexpectato gubernaculi pinnicidio subtus involutus assultum atque impetum primum fregisset; extemplo enim hinc animum navita inhaerentem adhuc cymbae ursum lancea traiicit (p. 129). 
esta segunda navegación fue dirigida, como la primera, por Willen Barentz (Wilhelmus Barentzonius), ayudado por Jacob van Heemskerk (Iacobus Heemskerkius), que sería el almirante de expediciones posteriores. Muy pocos datos históricos nos da Pontano de esta expedición. Pero al final de la misma, en septiembre de 1595, llegan a la isla descubierta en la expedición anterior, llamada Statem Eylandt o Ordinum insula. Estando en ella, antes de volver a Holanda, nos describe Pontano un relato siniestro:

En ella había abundancia de liebres y cazaron muchas. Y a algunos de los marineros, en una salida a la parte del continente que está frente a la isla, les ocurrió un siniestro suceso. Mientras dos de ellos, alejándose de los demás, buscan piedras, que se encontraban no solo allí, sino también en la isla Ordinum, pensando que por su brillo eran diamantes, les asaltó de pronto un enorme y flaco oso que atacando por detrás a uno de ellos mientras estaba agachado le trituró la cabeza. El otro que estaba al lado, al verlo, echó inmediatamente a correr contando a los compañeros lo que había sucedido. Éstos, en número de veinte, pertrechados con espadas, lanzas y otras armas se dirigen al lugar de la carnicería con la esperanza al menos de quitar el cadáver al oso. Y ya se habían colocado en fila de ataque, cuando el oso que estaba pegado al cadáver, dejándolo un poco al lado, saltó con gran violencia contra ellos y subiéndose sobre uno de los que estaba en medio de la fila, lo destrozó de forma cruenta, mientras los demás huían. Los que estaban en las naves, al ver huir a los suyos, enviaron en su ayuda algunos marineros más. Se plantearon atacar al oso uniendo todas sus fuerzas, pero les pareció mejor idea que se adelantaran dos o tres y le lanzaran piedras. Esto, sin embargo, cuando lo hicieron, tuvo poco éxito. Por ello, se adelantó un cuarto marinero y poniéndose junto al oso dirigió la espada a la frente y, lanzado un golpe, el oso, reteniendo de todas formas el cadáver en la boca, dio la impresión de que se encrespaba; pero cuando se dieron cuenta de que poco a poco empezaba a tambalearse, se acercaron más dirigiendo sus armas y espadas contra el oso que todavía no soltaba el cadáver. Al final un marinero, saliendo del grupo, lanzó con gran fuerza el puño de la espada contra el rostro del animal y con este golpe, como tocado por un rayo, cayó ${ }^{44}$.

${ }^{44}$ In ea leporum erat venatus copiosissimus plurimosque ceperunt. Nonnullis vero ex navalibus in continentem quae insulae ex adverso sita est progressus perquam sinister accidit. Dum enim unus alterve a caeteris longius aberrans lapillos quaeritat, qui non ibi modo, sed in insula quoque Ordinum reperiebantur, fulgore adamantes referentes, accurrit inopinato grandis ac macilentus ursus, qui postico invadens decumbentem alterum occiput ei mandibulis confringit; alter, qui aderat, re adnimadversa, in pedes extemplo se coniicit, enarrans sociis quos accidisset. Hi viginti numero sclopetis, lanceis aliisque instructi armis ad locum lanienae progressi ea spe, ut saltem cadaver urso eriperent. Et jam se in statum praeliarem composuerant, cum ursus cadaveri inhaerescens, idemque paulisper deferens magno in eosdem impetu prosiliit, et unum insuper ex media turba proripiens miserum in modum, fugientibus reliquis, dilaceravit. Qui in navibus erant fugientes suos conspicati, aliquot classiariis missis, suppetias accessere. Deliberatum an iunctis viribus ursum invaderent, verum consultius visum, ut duo tres antel gressi paululum, in eum sclopos emitterent. Quod ubi factum esset parum tamen pensi habuit, ideoque et quartus anterius adhuc procurrens collimansque in frontem ursi sclopetum direxit, verbereque emisso, cadaver nihilominus ore retinens attollere cervicem visus est, sed vertigine cum agitari paulatim animadverterent accessere propius armaque et enses in eum distringentes nolentem adhuc cadaver amittere, dum tandem ex turba accurens unus maximo nisu sclopeti capulum in rostrum eius adegit, eoque ictu veluti fulmine tactus corruit (pp. 133-134). 
Es una descripción propia más bien de un ejercicio retórico que de un relato histórico: se insiste en detalles cruentos (el oso trituró la cabeza al hombre; el lugar se convirtió en lugar de la carnicería; el oso destrozó al hombre de forma cruenta; retuvo largo tiempo el cadáver en la boca); en contrastes (era un oso enorme y flaco; empezó a erguirse encrespado, pero en realidad era una violenta sacudida para después tambalearse y caer); en intriga (parecía que aquel oso no acabaría nunca de morir ni de soltar de sus fauces el cadáver del hombre); en metáfora épica (el oso cayó como tocado por un rayo).

\section{DESCRIPCIÓN DE LAS CARACTERÍSTICAS RARAS Y EXTRAÑAS DE LOS PUEBLOS INDÍGENAS}

En el año 1595, al mismo tiempo que salía, como hemos visto, una expedición hacia el polo norte, fue organizada otra para que siguiera hacia las Indias el camino portugués, bordeando África; se trata de la ya citada Indica Amstelodamensium navigatio prima eiusque historia ordine posita. Al pasar por el cabo de Buena Esperanza, muchos de los marineros desembarcan, para buscar sobre todo comida con la que recuperar a los enfermos. Aprovecha el momento Pontano par describir a los habitantes de la zona, exagerando, como es propio, los rasgos extraños de los mismos; se trata de los khoikhoi ${ }^{45}$. Dice:

Habita aquí una raza de hombres bárbaros por encima de lo que se pueda decir. Son de pequeña estatura, pero de una composición corporal digna. Emiten un sonido, o mejor un recóndito murmullo cloqueando a la manera de las gallinas. Andan desnudos en la mayor parte del cuerpo, salvo que atan tiras de pieles sin curtir en sus sandalias y tapan sus partes pudendas con colas de zorras o de otras fieras. Los que pretenden parecer más honorables utilizan mantos de diversos colores. Algunos pensaron que había que deducir que eran antropófagos porque se alimentaban de carnes crudas, devoraban ansiosamente las tripas y demás entrañas, sin apenas limpiar la mierda, y roían los huesos como lo perros; de ahí que sus bocas mismas malolieran, como podían comprobar los marineros desde lejos, los cuales afirmaban que eran monórquidos, es decir que cada uno de ellos tenían in solo testículo; y que por ello su voz era tenue y gallinácea ${ }^{46}$.

${ }^{45}$ Los khoikhoi, más conocidos como hotentotes, son un pequño grupo étnico nómada del África del suroeste, específicamente de Botsuana y Namibia, que se separó de los Khoisán. Llegaron a esta región a principios del siglo VI. Están estrechamente relacionados con los grupos San o Bosquimanos. Sus lenguas se clasifican dentro de la macro-familia Khoisan, que al igual que la lengua de los Damaras, los Namaqua y los Hadzas, se caracterizan por usar chasquidos que hace de estas lenguas un algo tan característico. Son de piel oscura con estatura promedio de $1,50 \mathrm{~m}$.

${ }^{46}$ Habitat hic genus hominum supra quam dici potest barbarum. Brevi sunt statura, sed tamen apta membrorum compositione. Sonum potius et inconditum murmur ad instar gallinarum glocitantes edunt, quam sermonem articulate distinctum. Nudi magnam partem incedunt, nisi quod crudarum pellium segmenta soleis 
Nótese cómo Pontano hace hincapié en rasgos extraños de los hotentotes: son bárbaros por encima de lo que se pueda decir; hablan de una forma muy rara, como las gallinas cuando cloquean; van desnudos; deben ser antropófagos porque comen carne cruda y vísceras sin limpiar; tenían un solo testículo. Las leyendas dicen que los hotentotes quitaban un testículo a sus hijos pequeños, para que no tuvieran gemelos.

Llevado por su deseo de exponer lo sorprendente, es decir lo que llama la atención, Pontano a veces se contradice. Acaba de decir que aquellas gentes eran bárbaros en extremo; pero un poco más adelante, con tal de destacar un hallazgo sorprendente, apunta que estas gentes no vivían en estado salvaje: el hecho sorprendente es que al lado de un camino encontraron dos manos humanas cortadas y colgadas en dos palos (in reditu iuxta viam binas offendunt manus intra duo ligna defixas); esas manos le habían sido cortadas a un individuo que había robado bananas; ello indica claramente, añade, que el derecho y las leyes regían entre aquellas gentes (iura et leges apud eosdem vigere manifestum est, p. 151). Domina el deseo de exponer lo que choca o llama la atención: en un momento destaca el comportamiento salvaje de esta gente; en otro, destaca el hallazgo de dos manos cortadas y colgadas de dos palos, que es explicado como castigo a un ladrón; y de ahí concluye que no eran salvajes, sino que tenían sus leyes y derechos.

La verdad es que la mutilación de las manos en el caso de los ladrones no es una prueba de justicia y derecho. Se trata de una costumbre muy extendida en pueblos antiguos; y, cuanto más antiguos y rudos, más crueles son los castigos para los que no cumplen la norma. De manera que lo que hace Pontano es aplicar a estos pueblos bárbaros una costumbre de pueblos antiguos y que no dejaba de ser, aunque ruda y cruel, una forma de administrar justicia. Este detalle de indigenismo llama la atención y sorprende, pero interpretado desde parámetros occidentales es frecuente en Pontano. El indigenismo llamativo sorprende, pero es explicable.

Un caso muy significativo al respecto es el relato de las costumbres religiosas de los habitantes de Bali (pp. 191-192). Comienza diciendo Pontano que su religión es una religión étnica; es decir, una religión que sólo practica un grupo cerrado de etnias, en concreto las etnias indias (Religionem balenses omnes ethnicam sequuntur, cuiusmodi fere, exceptis mohumetanis, Indi reliqui). Pero a continuación enumera usos religiosos que unas veces son étnicos y otras, universales; compartidos, por ejemplo, con el islam o con el cristianismo. Recuerda que en Bali los sacerdotes son muy respetados y honrados (Maximo in honore babent sacerdotes, quos bramenes sive brachmanas

suppingunt partesque obscenas vulpium aut aliarum ferarum caudis velant. Qui lautiores videri volunt palliis diversicoloribus utuntur. Antroppohagos (sic) esse eo colligendum nonnulli putarunt, quod carnibus crudis vescerentur; et omasum et reliqua exta, faecibus leviter eiectis, avide vorarent et ossa denique veluti canes arroderent; unde et oris ipsis graveolentia, quam etiam eminus persentiscerent classiarii, qui monorches (de un solo testículo), id est singulis singulos esse testiculos affirmabant; eique rei argumento etiam esse vocem tenuem et gallinaceam (pp. 146-147). 
vocant) y que ellos son los depositarios de la ciencia divina y humana (Penes hos arbitrantur esse rerum divinarum et humanarum scientiam); esto es aplicable a cualquier religión universal y no sólo a las etnias orientales; aunque bien es cierto, que quizás esos rasgos se han mantenido más rígidos en las religiones étnicas orientales que en las universales de occidente. La religión del pueblo hebreo del Antiguo Testamento, que era una religión étnica, ya que era cerrada y seguida sólo por un grupo étnico, tenía del sacerdote la misma consideración que acabamos de ver en la definida por Pontano para Bali; sin embargo, el cristianismo, que es una continuación de la religión del Antiguo Testamento, es ya una religión universal; y en él, la consideración del sacerdote se va relajando cada vez más y apartando de la que tenía en las religiones étnicas orientales. Por ello quizás Pontano hace hincapié en esta consideración del sacerdote en la religión étnica de los orientales.

Sigue el humanista exponiendo rasgos propios de la religio ethnica de Bali: nadie puede llegar a rey, si no se ha sido instruido por el sacerdote (Reges nulli sunt qui non sint prius eorum disciplinis imbuti); se trata de la unión entre poder político y poder religioso, que durante mucho tiempo se mantuvo en el cristianismo y se sigue manteniendo en el islam, a pesar de ser religiones universales. Y añade Pontano que en Bali los sacerdotes pueden andar para un lado y otro sin ser molestados, incluso en tiempo de guerra (Tempore belli fas illis ultro citroque secure ac tuto commeare); y es que se considera crimen imperdonable tocar a los sacerdotes de forma diferente a como exige su reconocida santidad (Inexpiabile namque scelus existimatur illos secus quam postulat opinio sanctitatis attingere); esos sí son rasgos peculiares. Pero inmediatamente sigue con rasgos que son propios del cristianismo. Dice, en efecto, que los sacerdotes de Bali llevan tres cintas desde el hombro derecho al costado izquierdo como símbolo de las tres manifestaciones de la naturaleza divina (Terna fila ab humero dextro in latus sinistrum gerunt, ut designent trinam in natura divina rationem); y que creen que Dios, revestido de forma humana, limpiará el mundo para librar al género humano de la muerte eterna (Credunt deum in specie humana latentem terras lustravisse, ut humanum genus a peste sempiterna liberaret). Son rasgos propios del cristianismo, pero que a Pontano debieron parecerle tan exóticos que dice que originariamente eran propios de la religión oriental y que fue el cristianismo el que los tomó de allí (Quae sane a christianis antiquissimis accepisse verisimile est).

Y vuelve a rasgos propios de la religión oriental que son claramente exóticos para los occidentales. Así, el hecho de que las ceremonias sagradas sean presididas no sólo por los sacedotes, sino también por sus mujeres (Sacris non ipsi tantum, sed et mulieres ipsorum praesunt). Y el hecho de que, aparte de los bhramanes, hay otro tipo de individuos santos, llamados baneanes, que llevan colgando del cuello una piedra taladrada del tamaño de un huevo, de cuyo agujero cuelgan tres hilos; y dicen que esta piedra tiene un profundo significado numínico y que por ello es llevada con gran respeto por todos; esa piedra de tan profundo significado religioso se llama tambarane (Est et aliud hominum genus, quod valde etiam sanctum habetur. Hi baneanes appellantur. Lapidem ovi magnitudine pertusum, e cuius foramine tria fila prodeunt, e collo appensum gestant. Huius lapidis significatione summum numen contineri praedicant, et ea de causa maximo honore ab omnibus afficiuntur. Lapis tanta religione cultus tambarane nominatur). Esos individuos no comen carne ni pescado y se abstienen del matrimonio 
y de venus, pero no totalmente, porque se casan una vez en la vida y, cuando ellos mueren, su esposa es enterrada viva junto a su cadáver (A carnibus et piscibus abstinent; quod cum pythagoreis iavanensibus, de quibus supra dixi, commune habent, in eo diferentes, quod haud in totum, ut iidem Iavanenses, a matrimonio omnique venere se abdicent. Semel namque in vita uxorem ducunt. Illis defunctis, uxores prope illorum cadavera vivae supeliuntur...); practican el ascetismo y el rechazo a las cosas de este mundo; no tienen riquezas; se alimentan de lo que piden; recorren todas las plazas, para comunicar la disciplina de su secta a los oídos de todos (Prae se ferunt hi singularem rerum humanarum contemptionem. Nullas opes possident; mendicatis cibis victitant; per omnia fora cursant, ut suae sectae disciplinam omnium auribus inculcent). Todos ellos son comportamientos extraños y raros; exóticos, en definitiva. Y termina Pontano con un comportamiento de estos sacerdotes, no extraño ni exótico, sino propio de pueblos incivilizados e ignorantes: la mayor parte de esos sacerdotes, dice, engaña con sus artilugios a aquellos hombres ignorantes y abusa, para su propio interés, de la demencia de ellos (Maxima eorum pars praestigiis illudit hominibus imperitis eorumque dementiae ad suum quaestum abutitur).

E igualmente propio de gentiles incivilizados es la costumbre que añade al final, a la que ya ha aludido de pasada antes:

Todos los indios que son aún gentiles conservan todavía hoy esta costumbre: muerto el marido, incitan a las mujeres todavía vivas a arrojarse a la pira acompañándolas un gran séquito de familiares que van cantando canciones y loas. $Y$ a las que se niegan a ser quemadas en el fuego de su marido y a subir a la misma pira, las consideran poco buenas esposas; sin embargo, a las dispuestas y obedientes las cosideran muy honestas, muy amantes de sus maridos y dignas de seguir viviendo con él en la otra vida ${ }^{47}$.

Esta es una vieja costumbre atribuida a los orientales por los antiguos (Propercio, iii 13. 15ss.). Pero Pontano añade una malévola explicación propia de pueblos bárbaros: que hacían esto para prevenir la maldad de las mujeres que frecuentemente envenenaban a sus maridos cuando se cansaban de ellos (Tradunt recentiorum Itineraria consuetudinem hanc a rege quodam ideo introductum, ut mulierum proterviae [maldad] obviam iretur; quae maritos saepenumero, ubi eorum ipsas satietas caperet, e medio tollere venenis aliisque fraudibus non dubitabant).

Del reyezuelo de la isla de Santa María, que está al este de Madagascar, destaca la extravagancia de su aspecto externo:

Después, desembarcando en tierra saludan el Rey de la isla y le agasajan con algunos insignificantes objetos, como corales, espejos y círculos de cristal, cosas todas que

${ }^{47}$ Omnes autem indi gentiles hunc hodieque morem servant, ut uxores, defuncto marito, vivae in rogum eius magno cum suorum comitatu et multis cantibus atque laudibus inferantur...; easque mulieres, quae cum funere mariti comburi ac rogum eundem conscendere renuunt, parum probas haberi; promptas autem et faciles, honestissimas et viri amatissimas censeri et dignas quae illi in altera quoque vita cohabitent (p. 192). 
gustan mucho a aquella gente. El rey se distinguía por su negrura, el color, según él mismo, de la noche, y por dos cuernos a modo de tiara de obispo. Los del lugar le llamaban cheque ${ }^{48}$.

Del rey de Madagascar señala que cuando le llevan para que duerma, van delante cantando con un enorme cuerno y pulsando también solemnemente, a modo de triunfo, un cuerno ${ }^{49}$.

Merece la pena, a este respecto, recoger el siguiente rito de los bantenses: en el matrimonio, el varón recibe como dote cincuenta siervos, cuarenta mujeres casadas y cuarenta vírgenes:

El marido puede llevarse a su alcoba y a su lecho a esas mujeres casadas y a las vírgenes cada vez que quiera. Y a los hijos que nacen de ellas no les dejan venderlos, sino que tienen que darlos a la esposa legítima, como le fue dado Ismael a Sara. Una cosa, sin embargo, debemos considerar como detestable: que a las mujeres casadas obligan a matar a muchos de sus hijos, y a veces, tanto a las casadas como a las solteras, si se descubre que están embarazadas, las obligan a abortar ${ }^{50}$.

De la isla Patane, descrita en la segunda navegación a la Indias, destaca Pontano, junto a la producción de perlas y especias, la particularidad de que el mando en ella lo lleva una mujer, y además desde hace mucho tiempo:

Neccio, del que dijimos más atrás que, tras la batalla naval con los portugueses, dirigiéndose al Quersoneso áureo (Malaca) llegó a Patane, se llevó de allí a su patria, por esta misma época, una gran cantidad de pimienta y de aromas. Patane es una fortaleza levantada entre Sián y Malaca junto al mar; es la metrópolis de todo este territorio o reino, el cual, a partir del nombre de la fortaleza, tiene el nombre de Patane. Cuando estuvo allí Neccio, era una mujer la que ostentaba el imperio y estuvo al frente del reino, ella sola, unos quince años ${ }^{51}$.

${ }^{48}$ Postmodum quoque in terram progressi Regulum insulae salutant, et utensilibus aliquot levibus, ut coralliis, speculis et vitreis quibusdam globulis, quae omnia apud ipsos magno in pretio sunt, condonant. Rex ipse nulla re nisi nigrore ac noctis, ut ille loquitur, colore et cornibus binis ad modum tiarae episcopalis insignis erat. Indigenae eum Cheque nominabant (p. 150).

${ }^{49}$ dum autem dormitum deportatur, ingenti cornu praecentum est et tympano quoque, triumphi in modum, solenniter pulsatum (p. 151).

${ }^{50}$ mulieres vero virginesque eas omnes fas marito in thorum et cubile, cum libet, assumere; liberos autem, qui ex eis nascuntur, divendere leges non sinunt; sed geniti coniugi legitimae cedunt, quemadmodum Ismael Sarae. Vnum interim detestabile habendum quod ex natis iisdem multos ab uxoribus saepenumero interimi aut saltem, ubi concepisse mulieres illae virginesque depraehenduntur, abortum eis procurari memorent (p. 174).

${ }^{51}$ Neccius etiam, quem supra post navalem cum lusitanis pugnam, Patanam in aureum chersonesum profectum indicavimus, magnum piperis et aromatum numerum eodem hoc circiter tempore domum retulit. Est autem Patane iuxta mare, medio inter Sianum et Malaccam loco situm oppidum, totius territorii sive regni quod ab hac civitate denominationem Patanes habet metropolis. Cum ibi Neccius ageret a faemina imperium administrabatur, et tum quindecim plus minus annos regno sola praefuerat (p. 208). 


\section{CONCLUSIÓN}

En el relato de las expediciones holandesas a las Indias orientales a finales del siglo XVI se pueden encontrar sin duda datos valiosos para la historia de estas navegaciones. Pero juntamente a lo histórico y geográfico se encuentra también lo asombroso y la literario. Sobre todo, en lo que se refiere a las islas. Hemos recogido en este trabajo textos de Isacius Pontanus, autor de una Historia de Holanda, en la que recoge detalles de las citadas navegaciones, en los que se puede comprobar el gusto por lo maravilloso y lo retórico en las descripciones de las islas.

\section{BIBLIOGRAFÍA}

Da Costa Ramalho, Américo (1998): "Os humanistas e a divulgação dos descobrimentos», en íd., Para a História do Humanismo en Portugal (III), Imprensa Nacional - Casa da Moeda, Lisboa, pp. 135-154.

VAn Doorninck, Pieter Nicolaas - Molhuysen, P. C. (eds.) (1909): Brieven van en aan Jo. Is. Pontanus, 1591-1639, van Brederode, Haarlem [Versión digitalizada: https://www.delpher.nl/nl/ boeken/view?identifier=MMSFUBA02:000009195:00012\&coll=boeken\&cql\%5B\%5D= $\% 28$ title+exact $+\% 22$ Brieven+van+en+aan+Jo.+Is.+Pontanus $\% 2 \mathrm{C}+1595-1639 \%$ 22\%29\&rowid $=1$.

GilsAnZ PÉrEZ, Guzmán (2007): «El imperio comercial holandés en siglo XVII», Revista de Estudios económicos y empresariales 19: 47-106 [https://dehesa.unex.es:8443/handle/10662/2934].

DE Matos, Luís (1984): L'expansion portugaise dans la Littérature latine de la Renaissance, Fundação Calouste Gulbenkian - Centre Culturel Portugais, Lisboa - Paris.

SkOVGaARd-PeterSen, Karen (2001): Historiography at the Court of Christian IV (1588-1648), Museum Tusculanum Press, Copenhagen.

De Sousa Rebelo, Luís (1978): «Diogo de Teive, historien humaniste», en L'Humanisme portugais et l'Europe. Actes du XXI Colloque International d'Etudes humanistes. Tours, 3-13 Juillet 1978, Paris, pp. 465-486.

DE VEDIA, Enrique (ed.) (1947): Historiadores primitivos de Indias, Atlas, Madrid. 